\title{
Desenvolvimento de Processo Automático para a Reticulação Progressiva de Matrizes de Colágeno com Glutaraldeído
}

\author{
Gilberto Goissis, Domingos M. Braile, Aparecida F. Giglioti
}

Resumo: Este trabalho descreve a determinação de parâmetros para o desenvolvimento de um processo contínuo de tratamento do pericárdio bovino com glutaraldeído, para a produção de válvulas cardíacas. Os resultados mostraram que o tempo de reação do glutaraldeído com o pericárdio bovino é dependente da concentração e para concentrações de 0,001 à $0,05 \%$, no intervalo de 1 à 2 horas, compatível com o desenvolvimento de um processamento industrial de reticulação contínua. Sob condições estequiométricas a impermeabilização e a heterogeneidade da reação do glutaraldeído com o pericárdio bovino foi verificada ser concentração dependente, com heterogeneidade parcial ou totalmente removida, pelo tratamento com tampão glicina/borato.

Palavras-chave: Pericárdio bovino, reticulação, glutaraldeído, processamento, automação, biopróteses.

\section{Introdução}

As válvulas cardíacas são responsáveis pela regulação do fluxo sangüíneo, e devido a mal formação congênita, doenças reumáticas, sífilis, processos infecciosos, artrite e processos de calcificação, freqüentemente estas válvulas precisam ser substituídas por próteses mecânicas ou biológicas. Entretanto, os substitutos valvulares, apesar de propiciarem um aumento de sobrevida, devido a melhora da função cardíaca, não são isentos de complicações pós-implante ${ }^{[1]}$. Nas biopróteses o maior problema são falhas estruturais causadas por rupturas na superfície do material cuja conseqüência é a calcificação. Estas falhas estruturais estão associadas ao tratamento do pericárdio bovino ( $\mathrm{PB}$, matéria prima para confecção das biopróteses) com o glutaraldeído (GA), e apesar desses problemas referentes à performance das biopróteses pós-implante, principalmente a degeneração e a calcificação ${ }^{[2]}$, ainda é o método preferencial de reticulação. A reticulação tem como objetivo reduzir a antigenicidade e melhorar as propriedades mecânicas do PB pela reação do GA com $\varepsilon$-amino grupo de lisina (Lys) e hidroxilisina (Hyl) presentes no colágeno para formar ligações cruzadas (reticulação) do tipo base de Schiff. Entretanto, estas reações não são homogêneas em virtude da heterogeneidade do tecido e da química complexa do GA (Figura 1), cujas soluções são caracterizadas por misturas complexas em equilíbrio contendo GA livre, formas mono e diidratadas, 


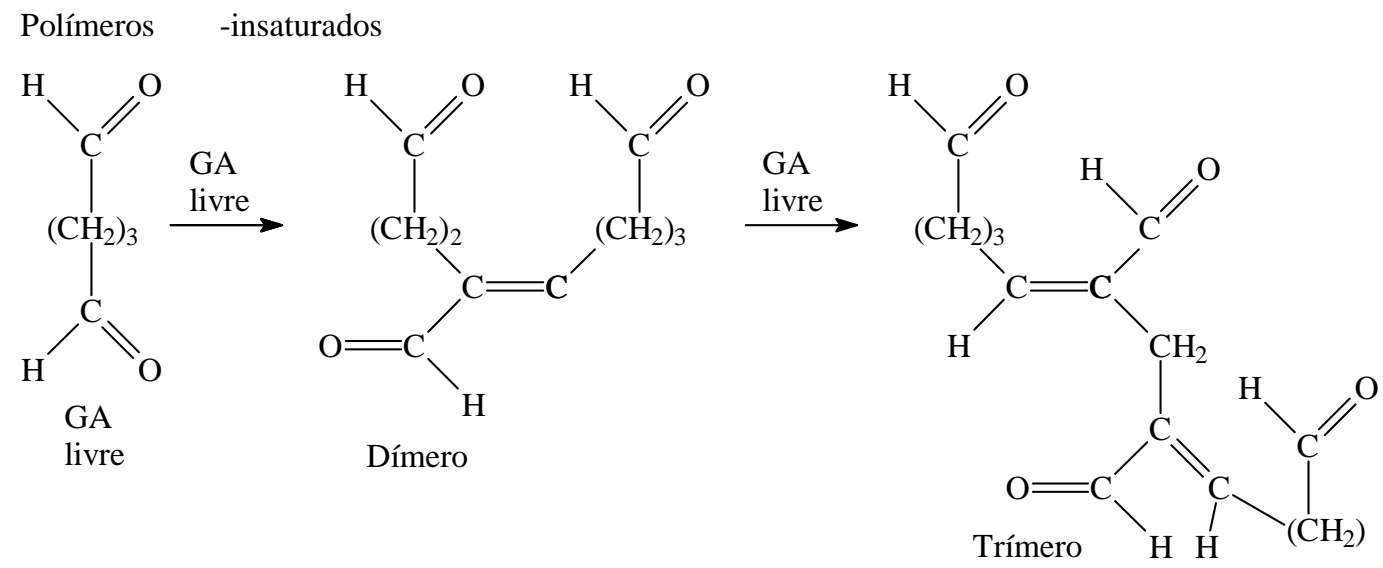

Figura 1. Formação de polímeros $\alpha, \beta$-insaturados a partir do Glutaraldeído

hemiacetais cíclicos (monomérico e polimérico) e vários polímeros $\alpha, \beta$-insaturados ${ }^{[3]}$.

Uma das resultantes da reação do GA com o PB é a impermeabilização superficial do tecido resultante da formação de ligações de reticulação poliméricas $^{[4,5]}$ do tipo poli-GA. Esta impermeabilização tem como resultado a presença na região interna da matriz de tecido que ainda mantem suas características originais ${ }^{[5]}$, que por exposição, após ruptura mecânica são responsáveis pelo início do processo de calcificação, prejudicando significativamente e de modo progressivo a performance hidrodinâmica das válvulas biológicas. Além da impermeabilização, as ligações cruzadas poliméricas são responsáveis também pela liberação de GA livre pós-implante, resultando em manifestações citotóxicas ${ }^{[6]}$.

Processos alternativos para minimizar os problemas da reticulação com GA tem sido introduzidos e incluem o pré-tratamento com éteres glicidílicos e hexametilenodiisocianatos ${ }^{[7]}$, glicerol ${ }^{[8]}$, azidas ${ }^{[9]}$, ou mesmo procedimentos alternativos utilizando o próprio $\mathrm{GA}^{[6,10]}$, tais como a fixação dinâmica ${ }^{[6]}$, o uso de temperaturas elevadas $^{[11]}$, ou ainda, o tratamento com concentrações progressivamente crescentes de $\mathrm{GA}^{[12]}$.

\section{Objetivo}

Em trabalhos anteriores ${ }^{[12]}$ foi mostrado que a reticulação progressiva do $\mathrm{PB}$ com soluções de GA de concentrações progressivamente crescentes, desde 0,001 até $0,05 \%$, em relação ao procedimento convencional (tratamento do PB com solução de GA $0,5 \%$ por 18 dias) dá origem a materiais mais homogeneos do ponto de vista da reticulação, como demonstrado pela maior estabilidade à colagenase e à tripsina ${ }^{[12]}$. Este trabalho teve com objetivo determinar a velocidade de reação do $\mathrm{PB}$ com o GA, com o propósito de desenvolver uma metodologia de reticulação progressiva por processo contínuo, visando a automação.

\section{Experimental}

\section{Materiais e Métodos}

O pericárdio bovino utilizado, fornecido pela Braile Biomédica (São José do Rio Preto), foi coletado de animais abatidos com idade entre 30 a 60 meses.

\section{Determinação do Tempo de Reação do} Glutaraldeído por meio do Corpo de Prova

Duas peças de PB de $4 \times 4 \mathrm{~cm}$ (quatro conjuntos) isentas de proteínas, foram tratadas com volumes estequiométricos de soluções de GA, e em tampão fosfato 7,4 , com concentrações variáveis de $0,001,0,005,0,01$ e $0,05 \%$. Esta estequiometria, baseou-se na reação de 1 mol de GA para 2 moles de $\varepsilon$-amino grupo de Lys e Hyl, cuja concentração total é de $4.3 \mu$-moles de $\mathrm{NH}_{2} / \mathrm{cm}^{2}$ de PB (concentrações de Lys e Hyl em PB são de respectivamente $4,5$ e $1,3 \mathrm{~g} / 100 \mathrm{~g}$ de colágeno) $)^{[13]}$. O tempo da reação de reticulação foi de 2 horas à $45^{\circ} \mathrm{C}$ e após os tempos de 10, 20, 30, 60 e 120 minutos foram adicionadas 3 peças de PB (corpos de prova) de dimensões de $2 \times 20 \mathrm{~mm}$, os quais foram deixados reagir por 5 minutos. Nestes mesmos intervalos 
amostras do material principal (peças de PB 4x4cm) também foram retiradas e a evolução da reação, tanto nos corpos de prova quanto nas amostras do material principal foram determinadas através da medida da temperatura de encolhimeto (Ts).

\section{Reticulação do PB Via Gradiente}

\section{Determinação da Curva do Gradiente atra-} vés da Norfloxacina

A um reservatório (reservatório 1) contendo 192 $\mathrm{mL}$ de uma solução $0,001 \%$ de norfloxacina e sob constante agitação foram adicionados com o auxílio de uma bomba peristáltica $192 \mathrm{~mL}$ de norfloxacina $0,005 \%$ (reservatório 2 ) com um fluxo de $192 \mathrm{~mL} /$ hora. O volume do reservatório 1 foi mantido constante. Após o término da adição no reservatório 2 , foram adicionados nas mesmas condições e em seqüência, soluções de norfloxacina de concentrações $0,01,0,05$ e $0,1 \%$ em TF. A monitoração do gradiente foi feita por spectroscopia de UV através de leituras do efluente $(\lambda=275 \mathrm{~nm})$ e para cada ponto de concentração após 15,30 e 60 minutos depois de cada troca de solução no reservatório 2. Volumes e velocidades de adição foram determinadas com base no tempo de reação determinada no item determinação do tempo de reação do glutaraldeido por meio de corpo de prova.

\section{Tratamento de Pericárdio Bovino com Gradi-} ente de Glutaraldeído

Trataram-se 2 peças de PB $(4 \times 4 \mathrm{~cm})$ isentas de proteínas com soluções de GA com concentrações variáveis de $0,001,0,005,0,01,0,05$ e $0,1 \%$ de acordo com o gradiente de concentração descrita para norfloxacina. O reservatório 1 , contendo $192 \mathrm{~mL}$ de solução $0,001 \%$ foi mantido sob agitação e a temperatura de $45^{\circ} \mathrm{C}$. A evolução do gradiente foi acompanhada por meio de corpos de prova como descritos anteriormente. A primeira avaliação foi feita com os primeiros $5 \mathrm{~mL}$ de efluente, ao qual foram introduzidos 3 corpos de prova de $2 \times 20 \mathrm{~mm}$ que foram deixados reagir por 5 minutos, seguidos de lavagens com TF $3 \times$ ( 2 minutos $), 1 \times$ (10 minutos $)$ em tampão $2,5 \times 10^{-2} \mathrm{~mol} / \mathrm{L}$ glicina: $5 \times 10^{-2} \mathrm{~mol} / \mathrm{L}$ borato (TGB) e mais $3 \times$ ( 2 minutos) em TF para posterior determinação de Ts. Procedimentos similares com corpos de prova foram realizados após 60, 120180 e 240 minutos de gradiente e também nestes mesmos tempos amostras circulares (PB) com cerca de $10 \mathrm{mg}$ foram removidas para análise térmica (DSC).

\section{Caracterização dos Materiais}

\section{Estabilidade Térmica:}

a. Temperatura de encolhimento (Ts): foram determinadas em um equipamento de ponto de fusão Quimis adaptado para Ts, utilizando-se amostras de 2 x $20 \mathrm{~mm}$. A taxa de aquecimento foi de $2,0^{\circ} \mathrm{C} / \mathrm{min}$ no intervalo de 20 a $100^{\circ} \mathrm{C}$. Os valores de Ts (média de 3 determinações), foram obtidos com as amostras imersas na solução TF, colocadas em um tubo de Pirex graduado de $20 \mathrm{~mm}$ imerso em banho de óleo de silicone.

b. Temperatura de desnaturação (Td): As temperaturas de desnaturação foram determinadas em amostras de PB previamente equilibrados em TF, em um equipamento TA INSTRUMENTS, modelo DSC 2010 calibrado com padrão de índio. A taxa de aquecimento foi de $10^{\circ} \mathrm{C} / \mathrm{min}$ de 20 a $180^{\circ} \mathrm{C}$. As amostras foram cortadas em discos (massas de aproximadamente $10 \mathrm{mg}$ ) e colocadas em cadinho de alumínio e a varredura realizada em atmosfera de $\mathrm{N}_{2}$.

\section{Espectroscopia de $U V$-Visível:}

Os espéctros (HITASHI -U3000) foram obtidos para o sobrenadante das reações de GA a $0.5 \%$ com PB em TF antes do tratamento com TGB, do sobrenadante tratado com TGB e das soluções resultantes do tratamento do pericárdio bovino com TGB. Este espéctros foram obtidos em função do tempo de reação à $45^{\circ} \mathrm{C}$ e entre 200 e $550 \mathrm{~nm}$.

\section{Resultados e Discussão}

\section{Estudo Cinético da Reação de Pericárdio Bovino com Glutaraldeído}

Como alternativa para determinação da cinética da reação do GA com o $\mathrm{PB}$, foi utilizada a técnica do 


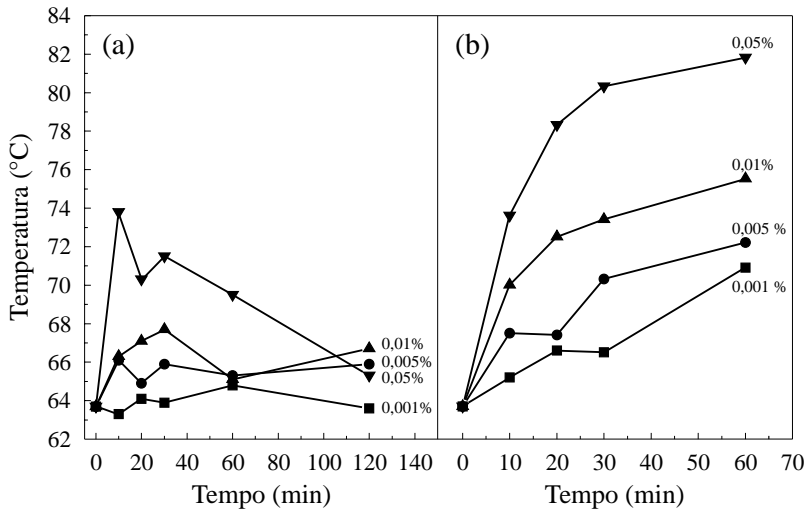

Figura 2. Temperatura de encolhimento $\left({ }^{\circ} \mathrm{C}\right)$ dos corpos de prova (a) e pericárdio bovino (b) correspondentes a reação com glutaraldeído nas concentrações entre 0,001 e $0,05 \%$, no intervalo de 0 a 120 minutos e na temperatura de $45^{\circ} \mathrm{C}$.

corpo de prova, visto que outras técnicas como por exemplo UV não se mostraram eficientes. A técnica do corpo de prova é uma medida indireta da concentração residual de GA das reações de reticulação em função dos valores de Ts e foi utilizada para a determinação dos tempos de reação do $\mathrm{PB}$ com concentrações variáveis de GA de 0,001 até $0,05 \%$.

Para as concentrações de 0,$001 ; 0,005$ e $0,01 \%$, o consumo completo do GA em solução foi observado após 60 minutos, pois os valores de Ts determinados para os corpos de prova foram próximos aquele do $\mathrm{PB}$ nativo que foi de $63,7 \pm 0,6^{\circ} \mathrm{C}$ (Figura 2a). Para a concentração de $0.05 \%$, o desaparecimento completo de GA foi observado apenas após 120 minutos de reação (Figura 2a). Entretanto, os resultados da Figura $2 \mathrm{~b}$ mostram uma característi- ca bastante peculiar para a reação do GA com o PB. Embora após 60 minutos do início da reação, os corpos de prova, para as concentrações entre 0,001 e $0,005 \%$ tivessem indicado a ausência do GA em solução, pois os valores de Ts foram praticamente iguais àquele do PB nativo (Figura 2a), neste mesmo intervalo as amostras de PB mostraram aumentos progressivos no valores de Ts. Isto sugere que o GA em solução está sendo absorvido pela estrutura do PB induzindo a uma reticulação subsequente da matriz. Esses resultados foram confirmados através de um experimento independente pela reação do $\mathrm{PB}$ com uma solução a $0,005 \%$ de GA. De acordo com os resultados da Figura 2, após 1 hora de reação à $45^{\circ} \mathrm{C}$, a peça de $\mathrm{PB}$ apresentou um Ts de $72,2 \pm 0,1^{\circ} \mathrm{C}$ e como esperado o corpo de prova um Ts no valor similar aquele do $\mathrm{PB}$ nativo $\mathrm{e}$ de $65,3 \pm 1,0^{\circ} \mathrm{C}$, sugerindo a ausência de GA em solução. A reação foi deixada prosseguir por mais 24 horas e a ausência de GA após este período foi obtida através da adição de mais três corpos de prova. $\mathrm{O}$ valor de Ts não foi significativamente diferente daquele obtido após 1 hora de reação. Entretanto, o aquecimento por mais 1 hora a $45^{\circ} \mathrm{C}$, mostraram para o corpo de prova e para a peça de $\mathrm{PB}$ valores de $\mathrm{Ts}$ de respectivamente $65,9 \pm 1,7$ e $77,4 \pm 0,3^{\circ} \mathrm{C}$. Este incremento de $5^{\circ} \mathrm{C}$ na peça de $\mathrm{PB}$ está de acordo com a observação feita nas condições do experimento da Figura 2 e deve ser resultante de moléculas de GA presentes internamente na matriz do PB na forma livre ou polimérica.
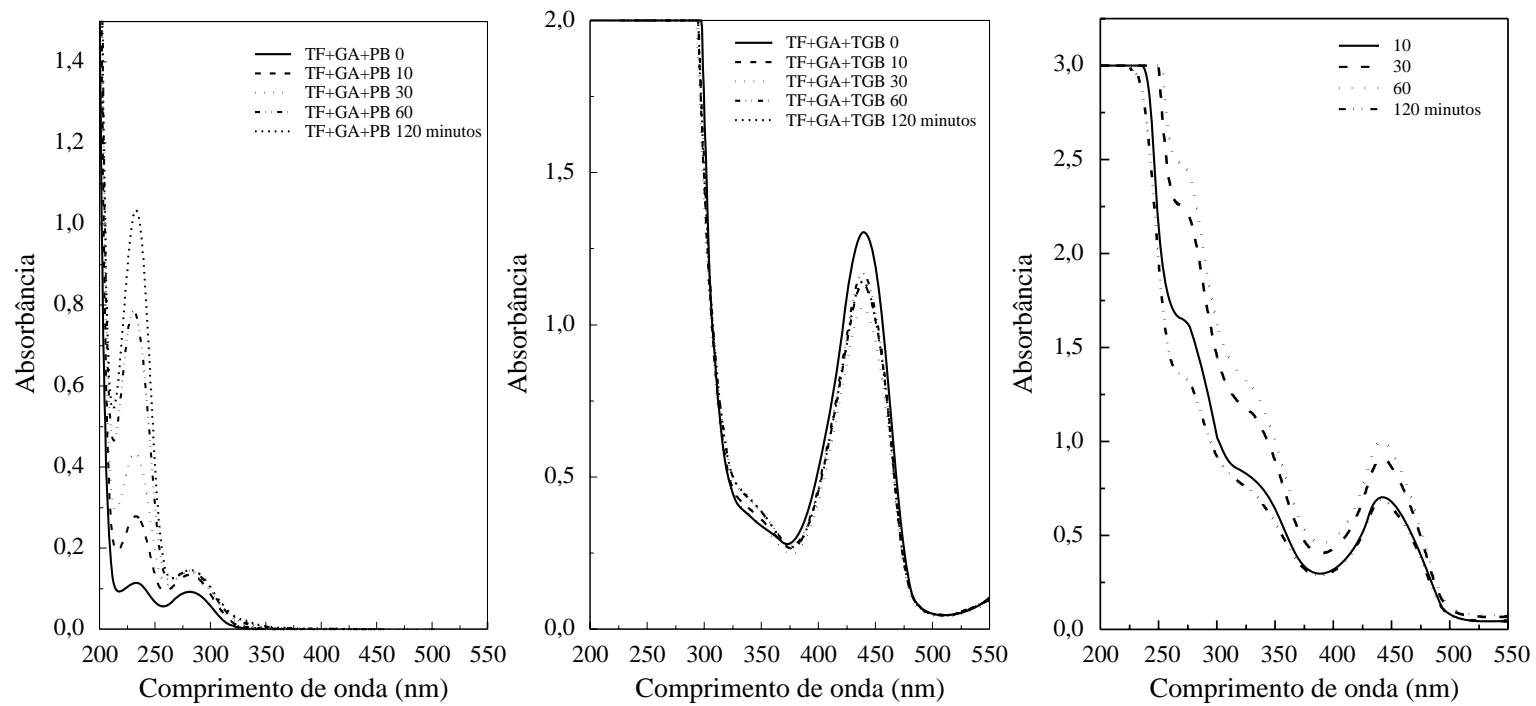

Figura 3. Espéctros de absorção das soluções resultantes da reação do pericárdio bovino em solução de glutaraldeído $0.5 \%$ em tampão fosfato 0.13 mol.L-1 $\mathrm{pH} 7.4$, em função do tempo de reação à $45^{\circ} \mathrm{C}$. Sobrenadante antes do tratamento com tampão glicina/borato (a); Sobrenadante tratado com tampão glicina/borato (b); Soluções resultantes do tratamento do pericárdio bovino com tampão glicina/borato (c). 
Tendo em vista os problemas que são atribuídos as biopróteses em conseqüência do uso do GA pós-implante, um estudo para eliminação desse GA residual foi desenvolvido. Neste caso a concentração de GA utilizada foi de $0,5 \%$ (concentração empregada para confecção de próteses) seguido do tratamento com TGB. O princípio do método é a reação do $\alpha-\mathrm{NH}_{2}$ grupo da glicina com aldeídos na forma livre ou polimérica para formar a base de Shiff. Como mostrado pela Figura 3b, o tratamento dos sobrenadantes resultantes das reações de GA com $\mathrm{PB}$, com TGB dá origem a um produto com $\lambda_{\max }$ em $439 \mathrm{~nm}$. Entretanto, a peça residual de PB quando tratada com TGB mostra a extração, além do produto com $\lambda_{\max }$ em $439 \mathrm{~nm}$, de um outro produto com $\lambda_{\max }$ em $334 \mathrm{~nm}$ (Figura 3c), que aparentemente está relacionado com a estrutura do $\mathrm{PB}$ como sugerido pelos perfis de DSC de amostras de PB tratadas com GA $0.5 \%$, seguidas de lavagens ou com TF ou com TGB (Figura 4).

No primeiro caso, para o PB lavado apenas em TF uma única transição foi observada em $87,0^{\circ} \mathrm{C}$. Entretanto, a lavagem com TGB produziu um perfil diferenciado que foi caracterizado por uma transição de menor intensidade em $87,5^{\circ} \mathrm{C}$

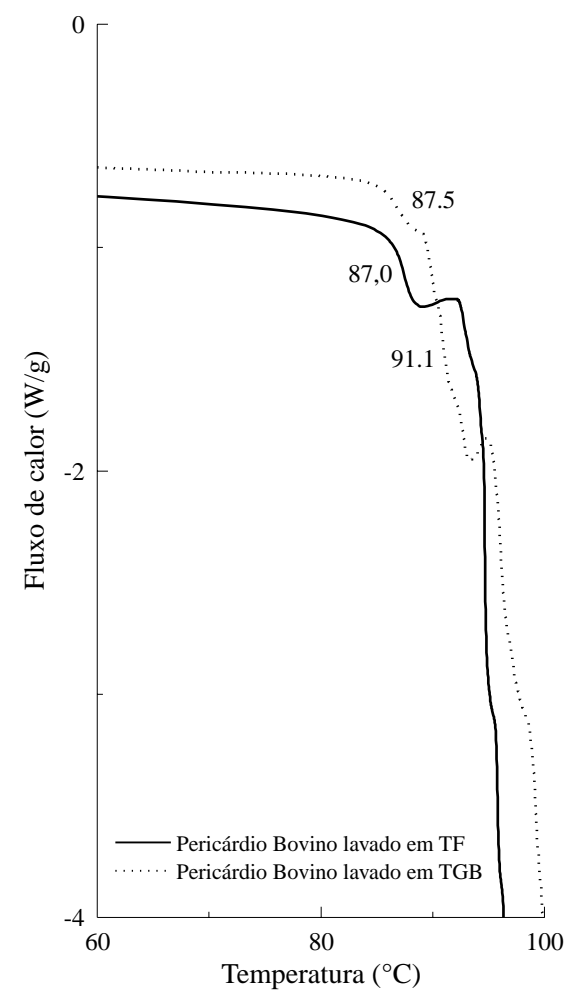

Figura 4. Curvas de estabilidade térmica para pericárdio bovino tratado com glutaraldeído $0.5 \%$, após 10 minutos de reação à temperatura de $45^{\circ} \mathrm{C}$. e uma principal em $91,1^{\circ} \mathrm{C}$, sugerindo claramente modificações no padrão de reticulação da matriz. Esse comportamento provavelmente é devido a algum tipo de interação química envolvendo GA e PB que é rompido pela glicina contida no TGB.

Para a determinação do gradiente, foi utilizada a norfloxacina devido a impossibilidade de qualquer tipo de determinação analítica que permitisse a obtenção desta curva com o GA, visto que no intervalo de concentração de GA para o gradiente $(0,001-0,1 \%)$ a variação da densidade ótica corresponderia a valores inferiores a 0,06 para a maior concentração utilizada de $0,1 \%$.

Para as condições experimentais utilizadas, o gradiente para a norfloxacina foi caracterizado por duas inclinações (Figura 5a), entre os intervalos de $0,001-0,05 \%$ e $0,05-0,1 \%$ e com coeficientes angulares de respectivamente $3,79 \times 10^{-6} \% / \mathrm{min}$ e $3,98 \times 10^{-}$ $5 \% /$ min. A Figura $5 \mathrm{~b}$ mostra as variações de Ts para os corpos de prova e para as peças de PB submetidas à reação por gradiente. Os valores de Ts determinados para os corpos de prova após os tempos de 60 e 120 minutos foram de respectivamente $63,8 \pm$ 0,3 e $64,9 \pm 0,3^{\circ} \mathrm{C}$, enquanto aquele para a peça de $\mathrm{PB}$ após o mesmo período foi de $73,0 \pm 0,9^{\circ} \mathrm{C}$.

De modo análogo ao observado na Figura 2a, e para o intervalo de concentração do gradiente entre 0,001 e $0,01 \%$ os valores de Ts para os corpos de prova e no intervalo entre 0 e 120 minutos foram similares àquele do $\mathrm{PB}$ nativo $\left(63,7 \pm 0,6^{\circ} \mathrm{C}\right)$ sugerindo que todo GA foi consumido e que neste intervalo de tempo a concentração efetiva de GA não ultrapassou 0,01\%. Assim como na Figura 2a, a introdução no gradiente da concentração $0,05 \%$ já mostra GA residual na solução, o que é evidencia-
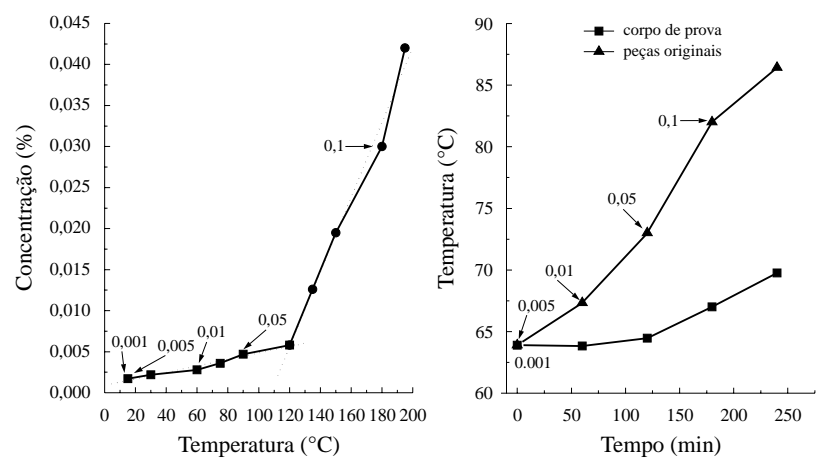

Figura 5. Curva de gradiente da concentração da norfloxacina em função do tempo de reação (a); Temperatura de encolhimento $\left({ }^{\circ} \mathrm{C}\right)$ dos corpos de prova e pericárdio bovino correspondentes ao gradiente da reação com glutaraldeído nas concentrações entre 0,001 e $0,1 \%$,no intervalo de 0 a 240 minutos e na temperatura de $45^{\circ} \mathrm{C}$ (b). 
do pelos aumentos de Ts dos corpos de prova. A partir desta concentração de GA as amostras de PB aumentaram suas estabilidades térmicas de modo quase linear e após 240 minutos de reação (término da adição $0,1 \%$ ) o valor de $\mathrm{Td}$ foi de $87,8^{\circ} \mathrm{C}$, valor este superior àquele aceito para a confecção de válvulas $\left(>84^{\circ} \mathrm{C}\right)$. Os valores de Td para as amostras de PB após o término de cada passo de concentração do gradiente 0,$005 ; 0,01$ e $0,05 \%$., foram de respectivamente 73,$3 ; 75,4 ; 84,7^{\circ} \mathrm{C}$.

\section{Conclusões}

Os resultados sugerem que parte da heterogeneidade da reação do GA com PB está associada pelo menos a dois componentes estruturais derivados do GA que podem ser removidos pelo tratamento com o tampão glicina/borato. Em relação a reticulação progressiva os estudos mostraram que nas condições estudadas, os tempos para reação completa do GA com PB em quantidades estequiométricas, é concentração dependente e de 60 minutos para concentrações até $0,01 \%$. Para a concentração de $0,05 \%$ o tempo de reação de 120 minutos é provavelmente resultante de processo de impermeabilização da superfície do PB. As relações de tempo, volume, gradiente e massa de GA determinados, são em uma primeira aproximação compatíveis para a automação do processo de reticulação do PB para produção industrial de válvulas cardíacas biológicas.

\section{Agradecimento}

Os autores agradecem a Ezer Biazin e Glauco D. Broch pela assistência técnica, à FAPESP (Proc $\mathrm{n}^{\circ}$ 96/02455-8) e RHAE/CNPq (Proc. $\mathrm{n}^{\circ}$ 610.048/ 96-1). AF Giglioti é bolsista FAPESP, Proc. $\mathrm{n}^{\circ}$ 98/ 03141-2, no programa de Mestrado em FisicoQuímica do IQSC, São Carlos - USP.

\section{Referências Bibliográficas}

1. Mc Giffin, D. C., O’ Brian, M. F., Galbraith, A. J., Mclachlan, G. J., Stafford, E. G., Gardner, A. H., Pohlner, P.G., Early, L., Kear, L. - An analysis of risk factor for death and mode specific death after aortic valve replacement with allograft, xenograft and mechanical valve. J. Thorac. Cardiovasc. Surgery. v. 106, p.895-911 (1994).

2. Lee, Y.S. - Morphogenesis of calcification in porcine bioprosthesis: insight from high resolution electron microscopic investigation at molecular and atomic resolution. J. Electron Microsc. v.42, p.156-165 (1993).

3. Woodroof, A. - Use of glutaraldehyde and formaldehyde to process tissue heart valves. J. Bioeng. v.2, p.1-19 (1978).

4. Cheung, D. T.; Natasha, P.; Ko, E. C.; Nimni, M. E. Mechanism of cross-linking of proteins by glutaraldehyde. II: Reaction with collagen in tissue. Connect. Tis. Res. v.10, p.201-206 (1982).

5. Cheung, D. T.; Natasha, P.; Ko, E. C.; Nimni, M. E. - Mechanism of cross-linking of proteins by glutaraldehyde. III: Reaction with monomeric and polimeric collgen in tissue. Connect Tis. Res. v.13, p.109-115 (1985).

6. Song, T.; Vesely, L.; Boughner, D. - Effects of dynamic fixation on shear behavior of porcine xenografts valves. Biomat. v.22, p.89-98 (1990).

7. Nairmark, W. A.; Pereira, C. A.; Tsang, K.; Lee, M. J. J. HMDC crosslinking of bovine pericardial tissues: a potential role of the solvent environment in the design of bioprosthetic materials. Mat. Sci. Med. v.6, p.235-241 (1995).

8. Xi, T.; Ma, J.; Tian, W.; Lei, X.; Long, S.; Xi, B. Prevention of tissue calcification on bioprosthetic heart valve by using epoxy compounds: a study of calcification tests in vitro and in vivo. J. Biomed. Mater. Res. v.26, p.1241-1251 (1992).

9. Petit, H.; Frei, V.; Huc, A.; Herbage, D. - The use of diphenylphosphoryl-azide for crosslinking of collagen biomaterials. J. Biomed. Mat. Res. v.28, p.159-165 (1994).

10. Goissis, G.; Yoshioka, S. A.; Braile, D. M.; Ramirez, W.; The chemical protecting group concept applied in the crosslinking of natural tissues with glutaraldehyde acetals. Int. J. Artif. Organs. v.22, p.210-214 (1998).

11. Ruijgrok, J. M.; Wijn, J. R.; Boon, M. E. - Optimizing glutaraldehyde cross-linking effects of time, temperature and concentrations measured by shrinkage temperature. J. Mat. Sci. Mat. Med. v.5, p.80-87 (1994).

12. Goissis, G.; Figueiró, S.d.; Braile, D. M.; Araujo, R.b.; Ramirez, V. D. A. - Reticulação progressiva de pericárdio bovino com glutaraldeído para confecção de valvulas cardiacas. Polímeros: Ciência e Tecnologia. v.8, n.2, p.46-54 (1998).

13. Ramachandran, G. N. - Treatise on Collagen. Chemistry of Colagen, vol.1, p.35 (1967). 